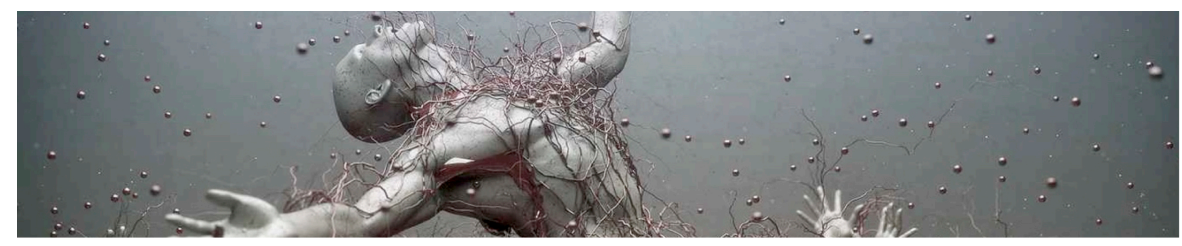

\title{
Mediación de las lógicas de producción hiperme- dia en el uso de la web 2.0 en Radio Sancti Spíri- tus. Un estudio de caso cubano
}

\section{Mediation of the Logics of Production Hyperme- dia in the Use of the Web 2.0 in Radio Sancti Spi- ritus. A Case Study Cuban}

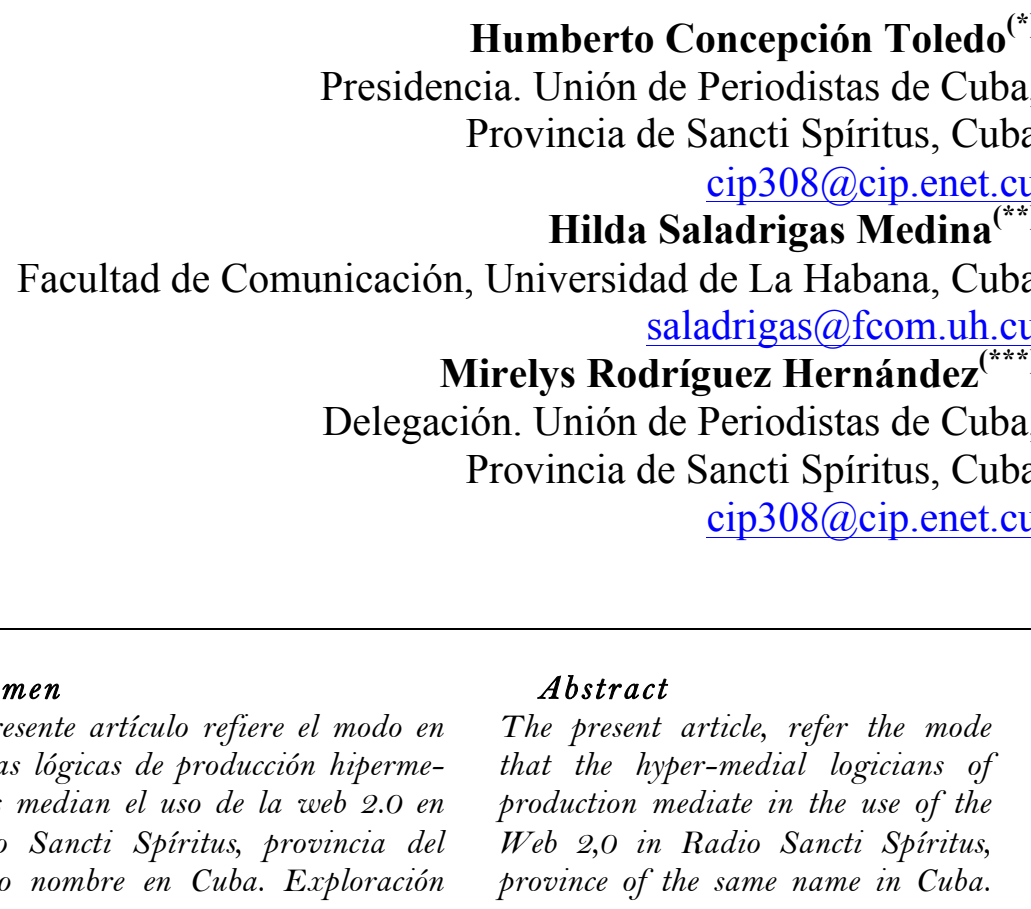


Humberto Concepción Toledo et al.

«Mediación de las lógicas de producción hipermedia en el uso de la web 2.0 en Radio Sancti Spíritus. Un estudio de caso cubano»

sin precedentes en el país refiere que tanto las mediaciones internas como las externas han estado articulando de manera dialéctica la evolución de las webs tradicionales hacia nuevas concepciones centradas en el usuario como eje del proceso comunicativo. La habilitación se evidencia en discretos avances en la filosofía 2.0, que hasta ahora implican un progreso superior en la disponibilidad de las aplicaciones requeridas para una mayor participación de los internautas que en las concepciones propias para lograr ese objetivo. A la vez, las constricciones provocadas han marcado a los productos comunicativos de manera que no expresan en toda su dimensión las transformaciones e innovaciones que prometen y permiten las tecnologías en el periodismo para y con Internet.

Palabras claves: mediaciones, lógicas de producción, periodismo hipermedia, lógicas de producción hipermedia, web 2.0.
He refers unprecedented exploration at the country that so much the internal mediations like day girls have been dividing the evolution of them into articles of dialectic manner Web traditional toward new conceptions centered in the user like axle of the communicative process. The preparation becomes evident in discreet advances in philosophy 2.0, the fact that until now they imply a superior progress in the availability of applications required for the inter-mariners's bigger participation than in conceptions own to achieve that objective. At the same time, they have dialed the provoked constrictions to the communicative products so that do not express in all his dimension the transformations and innovations that promise and permit the technologies in journalism stop and with Internet.

Keywords: Mediations, logics of production, journalism hypermedia, logics of production hypermedia, Web 2.0.

Sumario: 1. Introducción; 2. Desarrollo; 2.1. Mediaciones internas: 2.1.1. Institucionalidad; 2.1.2. Tecnicidad; 2.1.3. Cognitivas; 2.1.4. Estructurales; 2.2. Mediaciones externas: 2.2.1. Económicas; 2.2.2. Políticas; 2.2.2.1. Contexto político; 2.2.2.2. Política informativa; 2.2.3. Tecnológicas; 3. Conclusiones; Bibliografía.

\section{INTRODUCCIÓN}

El periodismo digital ha navegado desde 2004 hacia concepciones y aplicaciones sustentadas en la filosofía colaborativa de la web 2.0, si bien en el mundo ya se habla de la web 3.0. En este lapso, Internet ha evidenciado un tránsito de procesos comunicativos que iban de uno a uno o a muchos, a otro en el que los usuarios asumen un mayor protagonismo dentro de la dimensión comunicativa de los fenómenos que se presentan, una evolución que el catedrático español Mariano Cebrián resume en una

Mediaciones Sociales, № 13, 2014, pp. 3-36. ISSN electrónico: 19890494. 
Humberto Concepción Toledo et al.

«Mediación de las lógicas de producción hipermedia en el uso de la web 2.0 en Radio Sancti Spíritus. Un estudio de caso cubano»

frase: "Frente a la web impulsada por una institución, empresa o persona, surge la web en la que los participantes se sitúan al mismo nivel" (2008-a: 2).

Ante un esquema comunicativo que potencia la participación de los usuarios, los medios que se encuentran en la red enfrentan el reto de crear las facilidades para hacer efectiva una dinámica que conceda mayor prioridad a la intervención ciudadana. Ese panorama no escapa a la mirada de los medios espirituanos, en Cuba, integrados a la red de redes desde finales del siglo XX. No obstante, la realidad muestra un desaprovechamiento de las posibilidades que ofrece esta valiosa herramienta.

La pregunta está en por qué suceden tales comportamientos, en los que no se puede desconocer la incidencia de las dificultades con la base tecnológica y material, sin embargo estudios del desempeño profesional de los periodistas y otros productores de comunicación han indicado que la introducción de nuevas concepciones del hacer siempre han sufrido incomprensiones y resistencias, las cuales han estado mediadas por disímiles elementos, como sostiene el reconocido investigador José Luis Orihuela (2002:7): "Los medios tradicionales se enfrentan, con cada revolución tecnológica, a la apremiante tarea de reinventarse para sobrevivir".

Los estudios de emisores, particularmente los de carácter sociológico, han apuntado con diferentes categorías y sub-categorías las múltiples mediaciones que articulan/desarticular los procesos de producción periodísticas. En el año 2011, esta propia revista publicaba un artículo ${ }^{1}$ de autoras cubanas que ofrecía una proposición para estudiar lógicas de producción periodísticas en la web y sus mediaciones internas y externas.

El presente la toma como referente teórico-metodológico. Primero, consciente de que identificar los problemas que están presentando estas prácticas de modo riguroso, alejado de voluntarismos y subjetividades,

1 DIZ GARCÉS, Edda y SALADRIGAS MEDINA, Hilda (2011): «La categoría mediaciones en los análisis de las lógicas de producción periodísticas en la web», Mediaciones Sociales. Revista de Ciencias Sociales y de la Comunicación, $\mathrm{n}^{\circ}$ 9, pp. 35-72.

DOI: http://dx.doi.org/10.5209/rev MESO.2011.n9.38010

Mediaciones Sociales, № 13, 2014, pp. 3-36. ISSN electrónico: 19890494. 
Humberto Concepción Toledo et al.

«Mediación de las lógicas de producción hipermedia en el uso de la web 2.0 en Radio Sancti Spíritus. Un estudio de caso cubano»

permitiría trabajar de forma reflexiva en su neutralización y superación en pos de mejores desempeños que sitúen al ejercicio periodístico hipermedia a la altura de los tiempos que vive el país y las necesidades de participación ciudadana que exige actualmente la sociedad, y que resulta un derecho conquistado por el pueblo cubano.

Segundo, porque en las Ciencias de la Comunicación, y particularmente lo referido a la teoría de la Mediación Social es menester realizar estudios que sometan a validación científica sus presupuestos, y con ello enriquecer los acervos conceptuales, teóricos y metodológicos de este campo emergente en aras de necesarias sedimentaciones de los saberes.

Tercero, porque autores nacionales que se han acercado a esta temática (Naya, 2003; Recio, 2003; Bacallao, 2003; Rodríguez, 2005; SánchezComellas, 2005; Rodríguez, 2006; Díaz, 2008; García-Díaz, 2009; Ray, 2009; Croc, 2009; Terry, 2009; Diz, 2011; Companioni, 2012; Marrero, 2013; Elizarde, 2014) han definido, identificado y caracterizado un conjunto de dimensiones que habilitan o constriñen las prácticas profesionales del periodismo hipermedia en medios cubanos, sin embargo en la provincia Sancti Spíritus son escasos y desactualizados los acercamientos al tema (López, 2007; Obregón, 2009), y ninguno de ellos centrado en el tema de la web 2.0 en general, ni de la web de Radio Sancti Spíritus.

A partir de ello el estudio realizado, referido en este artículo, se planteó el siguiente problema de investigación científica: ¿Cómo median las lógicas de producción hipermedia el uso de la web 2.0 en Radio Sancti Spíritus, Cuba?

Planteo correlacional perseguía como objetivo general explicar el modo en que las lógicas de producción hipermedia median el uso de la web 2.0 en la emisora provincial de marras. Entre los objetivos específicos contempló sistematizar los presupuestos teóricos fundamentales relacionados con las lógicas de producción hipermedia en los sitios periodísticos digitales y la web 2.0; caracterizar a la Emisora Provincial Radio Sancti Spíritus como organización mediática; describir las lógicas de producción hipermedia que en ella tienen lugar, así como sus rasgos habilitantes y constriñentes en el uso de la web 2.0; reconstruir analíticamente el uso de la web 2.0 en el sitio web de la emisora radial e identificar en la producción comuni-

Mediaciones Sociales, № 13, 2014, pp. 3-36. ISSN electrónico: 19890494.

DOI: http://dx.doi.org/10.5209/rev_MESO.2014.n13.49431 
Humberto Concepción Toledo et al.

«Mediación de las lógicas de producción hipermedia en el uso de la web 2.0 en Radio Sancti Spíritus. Un estudio de caso cubano»

cativa hipermedial del sitio web estudiado las marcas de la mediación habilitante y/o constriñente de las lógicas citadas en el uso de la web 2.0.

La premisa que orientó el estudio se sustentó, tanto en referentes teóricos como en expresiones de la práctica no identificados y explicados en la unidad de análisis objeto de la investigación, lo cual no implicó el establecimiento de niveles de determinación que imposibilitaran la aparición de nuevos matices. Su formulación estableció que "las lógicas de producción hipermedia habilitan y constriñen el uso de la web 2.0 en el sitio web de Radio Sancti Spíritus. Habilitan en tanto conllevan la presencia de elementos pautados por la práctica en el terreno de la web 2.0 que se sustentan en la disponibilidad de una infraestructura tecnológica y del progreso de las competencias profesionales y comunicativas del personal implicado. Constriñen porque están carentes de normas que pauten su desempeño y de estructuras organizativas que lo habiliten, lo que repercute en un producto comunicativo distante del lenguaje del periodismo hipermedia”.

A partir de ello se consideraron dos categorías de análisis: Lógicas de Producción Hipermedia y Web 2.0.

Las Lógicas de Producción hipermedia² son concebidas como la "Estructura y dinámica de la producción periodística en medios webs, que deben diferenciarse de las lógicas de producción tradicionales por las modificaciones que las tecnologías de la información y la comunicación introducen en la producción, circulación y apropiación de la información, al tener lugar procesos que se distinguen en cuanto al lenguaje, que es hipertextual, multidireccional, interactivo y multimedial, que debe estar respaldado por competencias profesionales y comunicativas particulares, y la reconfiguración de la cultura profesional de los periodistas. En este proceso están presentes múltiples mediaciones, que relacionan dialécticamente toda su manifestación” (Diz, E., 2011:7).

Para la observación empírica de esta categoría, se aceptaron las dos dimensiones propuestas: mediaciones internas y mediaciones externas con los siguientes indicadores:

2 Esta investigación se acogió al concepto que sustenta la cubana, hoy Doctora en Ciencias de la Comunicación Edda Diz en su tesis en opción a ese título.

Mediaciones Sociales, № 13, 2014, pp. 3-36. ISSN electrónico: 19890494.

DOI: http://dx.doi.org/10.5209/rev_MESO.2014.n13.49431 
Humberto Concepción Toledo et al.

«Mediación de las lógicas de producción hipermedia en el uso de la web 2.0 en Radio Sancti Spíritus. Un estudio de caso cubano»

1. Mediaciones internas:

1.1. Institucionalidad:

1.1.1. Estructura organizativa de la redacción;

1.1.2. Recursos materiales;

1.1.3. Tipología del medio;

1.1.4. Normas de redacción;

1.1.5. Agenda informativa;

1.1.6. Socialización de saberes;

1.1.7. Política de estimulación salarial.

1.2. Tecnicidad:

1.2.1. Uso de Sistema de Gestión de Contenidos (CMS);

1.2.2. Computadoras conectadas;

1.2.3. Servidores;

1.2.4. Tarjeta para captura de video;

1.2.5. Cámaras fotográficas y de video;

1.2.6. Grabadoras;

1.2.7. Celulares.

1.3. Cognitivas:

1.3.1. Producción propia para la web;

1.3.2. Concepción del acontecer que se refiere;

1.3.2.1. Novedad;

1.3.2.2. Actualidad;

1.3.2.3. Agendas de referencia;

1.3.3. Autoregulación individual;

1.4. Estructurales:

1.4.1. Conocimientos y habilidades para el periodismo hipermedia;

1.4.2. Identificación del sitio (cabezal) y secciones;

1.4.3. Uso de imágenes (fotos, infografías, galerías, caricaturas);

1.4.4. Atributo ALT y pies de fotos;

1.4.5. Uso de Géneros periodísticos;

1.4.5.1. Tradicionales;

1.4.5.2. Emergentes;

1.4.6. Morfología de los productos comunicativos en cuanto a: la hipertextualidad, la interactividad y la multimedialidad.

Mediaciones Sociales, № 13, 2014, pp. 3-36. ISSN electrónico: 19890494.

DOI: http://dx.doi.org/10.5209/rev_MESO.2014.n13.49431 
Humberto Concepción Toledo et al.

«Mediación de las lógicas de producción hipermedia en el uso de la web 2.0 en Radio Sancti Spíritus. Un estudio de caso cubano»

2. Mediaciones externas:

2.1. Económicas:

2.1.1. Salario de los periodistas;

2.1.2. Otros ingresos estimulación salarial.

2.2. Políticas:

2.2.1. Contex to político;

2.2.2. Política informativa (regulaciones externas).

2.3. Tecnológicas:

2.3.1. Propiedades de Internet: conexión satelital y conectividad;

2.3.2. Desarrollo CMS para la prensa.

Para la Web 2.0 el estudio se acogió al concepto que la concibe formando parte de "Nuevas concepciones centradas en el usuario como eje del proceso comunicativo que determinan la evolución de las aplicaciones web tradicionales" (2009: 86)3. Esta actitud estimula la creación y publicación de contenidos, la generación de valor por los usuarios, el intercambio de información entre ellos, y la participación a través de plataformas más dinámicas, interactivas y de fácil navegación y la dimensionan en dos aristas:

1.1. Concepciones: Son actitudes, no tecnologías. La web es interpretada como un espacio de socialización colectiva, donde los servicios varían de un usuario a otro desde territorios y "capitales culturales" heterogéneos. El usuario es contribuyente y editor de los contenidos con libertad para crear y compartir en la Red. Esto implica una actualización y ejercicio constante de sus competencias de análisis, abstracción y síntesis del conocimiento.

1.1.1. Participación:

1.1.1.1. Interacción de los usuarios con los contenidos;

1.1.1.2. Interacción de los usuarios con los emisores.

1.1.2. Diseño:

1.1.2.1. Interfaz gráfica de usuario;

3 Aportado por las también cubanas Leidys García Chico y Daimy Díaz Breijo (2009), estudiosas del tema.

Mediaciones Sociales, Nº13, 2014, pp. 3-36. ISSN electrónico: 19890494.

DOI: http://dx.doi.org/10.5209/rev_MESO.2014.n13.49431 
Humberto Concepción Toledo et al.

«Mediación de las lógicas de producción hipermedia en el uso de la web 2.0 en Radio Sancti Spíritus. Un estudio de caso cubano»

1.1.2.2. Accesibilidad.

1.1.3. Convergencia multimedia:

1.1.3.1. Elementos multimedia que se utilizan;

1.1.3.2. Medida en que imágenes y/o sonidos complementan información textual;

1.1.3.3. Manera en que se combina los recursos multimedia;

1.1.3.4. Medida en que se explotan las potencialidades hipermediales de los ambientes web;

1.1.3.5. Formatos adecuados a lo más óptimo en cuanto a descarga y posibilidades de acceso del lector.

1.1.4. Interacción con redes sociales.

1.2. Aplicaciones 2.0: Basadas en tecnologías informáticas existentes para la creación de aplicaciones participativas con las que el usuario se erige como protagonista.

1.2.1. Redes sociales (presencia del medio).

1.2.2. Titulares y alarmas por email.

1.2.3. Sindicación de contenidos (RSS).

1.2.4. Promoción de noticias.

1.2.5. Podcast.

1.2.6. Servicios online (Mapas, diccionarios o glosarios, traductores, cursos educativos, carteleras de cine y televisión, clasificados, juegos, el tiempo, efemérides).

La unidad de análisis fue el sitio web de Radio Sancti Spíritus www.radiosanctispiritus.cu y la producción que el mismo exhibe. La selección obedeció a que, además de pertenecer al grupo de los primeros sitios creados en la provincia, muestra un desarrollo moderado en el uso de la web 2.0; resulta uno de los de mayor nivel de actualización y es representativo dentro del conjunto de sitios existentes en el territorio. Además, aporta a la línea de investigación donde se inserta el estudio por corresponderse con la composición de los sitios web en Cuba y las facilidades para la realización del estudio. También fueron considerados como unidades de análisis, en segundo lugar, sus productores directos e indirectos.

Mediaciones Sociales, № 13, 2014, pp. 3-36. ISSN electrónico: 19890494.

DOI: http://dx.doi.org/10.5209/rev_MESO.2014.n13.49431 
«Mediación de las lógicas de producción hipermedia en el uso de la web 2.0 en Radio Sancti Spíritus. Un estudio de caso cubano»

El método utilizado se sustentó en un criterio de diseño de estudio de caso único, el cual concibe un proceso de indagación caracterizado por el examen detallado, comprehensivo, sistemático y en profundidad del asunto objeto de interés del que debe derivarse una importante contribución al conocimiento y a la construcción teórica. Su empleo se sustentó, además, en cuatro características fundamentales: el ser particularista, descriptivo, heurístico e inductivo.

En su concreción se emplearon técnicas, cada una con su población y muestras específicas. Estas últimas fueron seleccionadas a criterio por la relevancia que tienen de cara al objeto de estudio. La investigación bibliográfica se usó para la sistematización conceptual y teórica que sustentó la definición de las categorías y sus dimensiones; el análisis documental para acceder a numerosos materiales de origen institucional, documentos normativos y valorativos del trabajo periodístico en general en la radio, particularmente en la producción informativa de la radio espirituana; la observación participante para el proceso productivo del periodismo hipermedia que tiene lugar en emisora provincial; la entrevista a directivos y periodistas, editores y webmasters con incidencia en la producción hipermedia unidad de análisis; la encuesta dirigida a los periodistas de la redacción tradicional, integrantes del equipo de producción informativa, para conocer los modos de asumir la virtualidad, y el análisis de contenido para profundizar en los elementos formales del producto en aras de valorar el empleo de los recursos expresivos y herramientas de Internet.

\section{Desarrollo}

Numerosos investigadores coinciden en señalar que la irrupción de la llamada revolución digital ha traído consigo profundas modificaciones en las formas de producción, circulación y apropiación de la información y ha alterado las relaciones de intercambios entre emisores y receptores. Ello hace que el campo profesional, académico e investigativo del periodismo hipermedia en el mundo esté aún en construcción, al no existir un vasto saber teórico-metodológico orgánico, coherente y riguroso al respecto, a pesar de la abundante y variada obra dedicada a un asunto en constante renovación.

Si bien en la última década el número de investigaciones en Cuba vinculadas al periodismo hipermedia denota un incremento progresivo, resul-

Mediaciones Sociales, № 13, 2014, pp. 3-36. ISSN electrónico: 19890494.

DOI: http://dx.doi.org/10.5209/rev_MESO.2014.n13.49431 
«Mediación de las lógicas de producción hipermedia en el uso de la web 2.0 en Radio Sancti Spíritus. Un estudio de caso cubano»

tan escasos los trabajos dedicados a abordar las lógicas de producción, un área en la que no se reportan evidencias que relacionen esta categoría con la presencia de la web 2.0 en un medio radial.

Desde esa perspectiva, la investigación que aquí se refiere indaga en un terreno sin precedentes, que adquiere mayor relevancia por tratarse de un estudio de caso de una emisora provincial, cuyo sitio web no ha sido objeto de estudios anteriores. De ello se desprende que sus resultados significan una importante aproximación empírica, valiosa para la toma decisiones en el medio en cuestión, un acercamiento metodológico desde la teoría de las mediaciones a la relación entre las lógicas de producción y usabilidad de las concepciones y aplicaciones de la web 2.0 en el medio radial, una contribución a la sistematización e integración de estudios precedentes y un aporte de resultados que contribuyan a la adopción de medidas necesarias para el ajuste y la solución de problemas aún presentes en este ámbito de la comunicación. Además contribuyó a la comprensión de los procesos que tienen lugar a lo interno de la producción comunicativa en las webs cubanas, pues mostró de manera científica las problemáticas existentes a fin de trazar estrategias para su superación y el necesario desarrollo de estas, en particular, y el periodismo hipermedia, en general.

Es importante señalar que si bien por una cuestión de análisis —que como método del pensamiento y la investigación - implica el abordaje del objeto mediante la mirada a sus diferentes componentes de modo separado, las mediaciones y las articulaciones/desarticulaciones que ellas establecen, no se pueden concebir de manera directa y bilateral, son más bien múltiples y recursivas.

\subsection{Mediaciones internas:}

\subsubsection{Institucionalidad.}

De acuerdo con las evidencias encontradas mediante la revisión documental, el nacimiento de una redacción digital en el año 2005, con plantilla de trabajadores definida y misiones predeterminadas por normativas del Instituto Cubano de Radio y Televisión (ICRT), marcó de tal manera el desempeño del sitio web de Radio Sancti Spíritus que hoy, a nueve años de su aparición, esa estructura es defendida por la mayoría de los periodistas por encima de los criterios administrativos que promueven la consoli-

Mediaciones Sociales, N 13, 2014, pp. 3-36. ISSN electrónico: 19890494.

DOI: http://dx.doi.org/10.5209/rev_MESO.2014.n13.49431 
«Mediación de las lógicas de producción hipermedia en el uso de la web 2.0 en Radio Sancti Spíritus. Un estudio de caso cubano»

dación de la redacción integrada. El 77 por ciento de los reporteros del medio tradicional encuestados resulta partidario de mantener la redacción digital por razones que giran en torno a las especificidades del medio y como una vía para elevar la eficacia y organización en la planificación del trabajo.

Ello ocurre en tiempos en que la administración busca consolidar la convergencia de las redacciones - lo cual es coherente con las tendencias prácticas y planteos conceptuales más contemporáneos sobre el particular-, y que se esboza más que por el compartimiento de un espacio para la composición de noticias, por el imperativo del enfoque hacia un concepto que tiene su basamento fundamental en el punto de vista, lenguaje y técnicas de realización con que se trabaja un tema, tanto para el medio tradicional como el emergente (Bello, 2014: 1).

De lo anterior se desprende, además de las consabidas resistencias al cambio, la existencia de vacíos en la conformación de un modelo que no debe limitarse a fusionar las redacciones, sino que debe estar acompañado de otros cambios estructurales, organizativos y conceptuales que repercutan favorablemente en una producción informativa distinguida por los recursos expresivos que deben caracterizar a cada medio.

Mediante la observación se pudo comprobar que la redacción digital dispone de las condiciones mínimas infraestructurales y organizativas para ejecutar su labor, sin embargo dista de objetivarse en la producción resultante la necesaria convergencia multimedia, resultado palpable de la no lograda aún convergencia estructural, a pesar de múltiples esfuerzos.

Resulta que la narrativa digital asume como propios códigos expresivos que pueden llegar a comunicar tanta o más información como el texto en sí mismo. Fotos, infografías y archivos de sonido y video, además de ofrecer mayor cantidad de información, dotan de diversas formas de acceso a los contenidos. Watzlawick, P. et al. (1991) han planteado al respecto que "El lenguaje digital cuenta con una sintaxis lógica sumamente compleja y poderosa”.

A pesar de las limitaciones que impone el ancho de banda disponible, la web de Radio Sancti Spíritus ha tratado de hacer suyo los recursos que hoy imprimen identidad propia a los sitios digitales como parte del empe-

Mediaciones Sociales, № 13, 2014, pp. 3-36. ISSN electrónico: 19890494.

DOI: http://dx.doi.org/10.5209/rev_MESO.2014.n13.49431 
Humberto Concepción Toledo et al.

«Mediación de las lógicas de producción hipermedia en el uso de la web 2.0 en Radio Sancti Spíritus. Un estudio de caso cubano»

ño por dejar atrás el volcado de contenidos de los medios tradicionales, si bien no lo han logrado del todo.

En esa dirección, tanto la observación como el análisis de contenido y las entrevistas realizadas evidenciaron que la oferta de audios bajo demanda, los fotorreportajes y la inclusión de imágenes fijas como complemento del texto, resultan las prácticas más comunes en la propuesta de la radio espirituana, que ubica en el propio cabezal una sección dedicada a estos recursos, posición de privilegio que evidencia la prioridad que se le concede dentro de la arquitectura general de la página. Ahí radica, lo habilitante de la mediación interna de la tecnicidad, pero a la vez lo constriñente de la mediación institucional, si dentro de ella se concibe la cultura profesional y la rutina productiva, así como la mediación individual cognitiva (conocimientos, habilidades y destrezas), las cuales expresan procesos humanos y sociales complejos que toman su tiempo en transformarse y ponerse a tono con las exigencias del momento.

El audio bajo demanda concentra tres ofertas principales: el Hit parade, Programas de radio y los Podcast o Podcasting (Gallego Pérez, 2010). Bajo esta categoría se agrupan los productos informativos que contienen audio y se presentan en una página específica en la que se integra texto, audio e imagen. Aunque los diseñadores de la web aplicaron esta concepción, el término Podcasting, expresión de la "innovación que surge tras la fusión de dos tecnologías ya implantadas: el audio digital y el RSS... y que permite la distribución y recepción automatizada de archivos de audio comprimido, tras una suscripción por parte del usuario a través de un agregador - software o web- que lo permita, y que una vez recibido este archivo, puede ser reproducido tanto en equipos estables como en reproductores portátiles o teléfonos móviles" (Gallego Pérez, 2010: 14), resulta más amplio y pudiera considerar a la generalidad de los materiales disponibles en la página, porque todos forman parte de la opción de distribuir contenidos sonoros a través de Internet y al margen de los medios tradicionales, lo que implica que la radio deja de tener la exclusividad del audio. De ahí que sea necesario reforzar otros atributos que le agrega Internet como soporte a la radio de manera que esta pueda construir su propia audiencia/usuario distinta a la que existe para la radio tradicional y el resto de los medios con presencia en la web.

Mediaciones Sociales, № 13, 2014, pp. 3-36. ISSN electrónico: 19890494. 
«Mediación de las lógicas de producción hipermedia en el uso de la web 2.0 en Radio Sancti Spíritus. Un estudio de caso cubano»

Más allá de esta precisión formal, directivos, editores y el webmaster reconocen como una fortaleza la distribución de podcasting, que a poco más de cinco años de su afianzamiento en el contexto universal, hoy se consolida como un soporte más para la distribución de los contenidos radiofónicos, por constituir una herramienta de enorme utilidad para el oyente, que puede decidir qué escucha, cuándo, cómo y dónde. Es quien en la unidad de análisis ofrece la posibilidad de brindar una suscripción para materiales específicos, con el inconveniente de que solo se oferta la ubicación de estos en la portada.

Con respecto a las imágenes, prevalecen las fijas, en mayor medida acompañando cada uno de los textos disponibles y como elemento fundamental de los fotorreportajes. Aunque el espacio ganado en su posicionamiento se considera una fortaleza por el webmaster, ello pudiera ser superior si contaran con todos los elementos informativos requeridos, lo que también haría más integral la propuesta para los usuarios.

Todos los entrevistados coincidieron al señalar entre las debilidades, los problemas de la conexión y las capacidades de almacenamiento de archivos, cuestión a la que atribuyen una menor presencia de videos, que generalmente son producidos por otros medios.

No obstante esta limitación, tanto por los recursos disponibles como por el potencial inexplotado resulta evidente la necesidad de trabajar con mayor intención la hipertextualidad como una vía para aprovechar mejor audios, imágenes y trabajos de fondo como complemento de otras propuestas informativas y hacer de la multimedialidad una herramienta más reiterada dentro de las propuestas de la web. Este fue un elemento que también afloró como limitante provocada por las mediaciones tecnológicas, internas.

No se puede olvidar que la radio en la web propone una interactividad abierta a los sonidos, a las imágenes y a la escritura. Es una modalidad diferente a la de la radio tradicional o a la navegación por Internet. Es una radio de comunicación interactiva que propone la difusión y también el almacenamiento de sonido así como el intercambio de información, debate y diálogo entre los usuarios. Establece un nuevo concepto de programación, el cual se centra en los consumos individuales pues cada usuario organiza su propio menú. El consumo se rige por los hábitos que al respecto

Mediaciones Sociales, № 13, 2014, pp. 3-36. ISSN electrónico: 19890494.

DOI: http://dx.doi.org/10.5209/rev_MESO.2014.n13.49431 
«Mediación de las lógicas de producción hipermedia en el uso de la web 2.0 en Radio Sancti Spíritus. Un estudio de caso cubano»

tiene el usuario de Internet, pues no establece demarcaciones fijas de tipos de programas, de tiempo, cantidad y frecuencia de uso. Adquiere nuevas características imbuido de sus elementos: navegación, hipertextualidad e interactividad.

"Escribir para Internet deviene un reto para los trabajadores de la radio, pues se trata de asumir un estilo de redacción diferente al que utilizamos cuando comunicamos a través del éter" (ICRT, 2005: 1). En tales términos se pronuncia la Carta de Estilo concebida por la Radio Cubana para las redacciones digitales y que hace suya Radio Sancti Spíritus.

Importante mediación interna de carácter institucional para la producción resulta desactualizada según resultados de la entrevista a directivos: "la Carta disponible, se elaboró en un momento teniendo en cuenta indicaciones de niveles superiores pero no ha tenido prolongación en el tiempo", sin embargo se reconoce la necesidad de proceder a su actualización dada su trascendencia para el trabajo cotidiano.

Si bien ello resulta evidente, el análisis de contenido realizado deja ver constantes deslices en la aplicación de las normas contenidas en la Carta de marras, falta de uniformidad en el tratamiento de cuestiones precisadas y otras carencias que denotan fallas en el dominio de las precisiones definidas en ella. Se puede afirmar que la normatividad en cuanto al quehacer periodístico para la web constituye una constricción más que por lo establecido en su letra, de por si desactualizado, mengua la labor del periodismo hipermedia por su inaplicabilidad debido al desconocimiento, girando el peso hacia la mediación institucional de carácter estructural-organizativa, ya que no existe control sobre su necesario empleo y como es lógico conocimiento, con lo cual también se involucra la mediación cognitiva de carácter individual.

Tal situación se confirma cuando el 89 por ciento de los periodistas de la redacción tradicional encuestados sostiene que no conoce las precisiones de la Carta de Estilo concebida para la web, lo cual, además, es una evidencia del divorcio existente entre la aspiración de disponer de redacciones integradas y la realidad en que se mueve el asunto en predios de la unidad de análisis estudiada.

Mediaciones Sociales, № 13, 2014, pp. 3-36. ISSN electrónico: 19890494. 
«Mediación de las lógicas de producción hipermedia en el uso de la web 2.0 en Radio Sancti Spíritus. Un estudio de caso cubano»

Para el cumplimiento de su misión principal, de acuerdo con lo apreciado tanto en los documentos rectores del trabajo como en las entrevistas a directivos y editores, el sitio web tiene definido el perfil editorial que concibe su actualización diaria mediante la publicación de materiales periodísticos y programas radiales (en audio bajo demanda) que reflejan los hechos y acontecimientos más trascendentales del territorio espirituano, Cuba y el mundo como vía para llevar este mensaje al exterior.

Bajo sus preceptos, también se proyecta dar prioridad al ámbito provincial y resaltar los logros tangibles que hoy se perciben en pueblos y comunidades del territorio como parte de un proceso editorial que responda a los planes temáticos que rigen la política informativa.

En su agenda, el sitio da espacio, además, al sostenimiento de un número de secciones fijas destinadas a promover los valores patrimoniales, musicales e históricos del territorio, especialmente a los pertenecientes a las villas de Trinidad y Sancti Spíritus, dos de las primeras siete fundadas por los españoles en la mayor de Las Antillas. De igual forma incluye otros subsitios que complementan la web y le aportan valor añadido.

El análisis de contenido realizado deja ver cierta correspondencia con tales principios si se toma en consideración que prevalece la información provincial por encima de las restantes, a razón de dos por una, para lo que se apoya en el empleo no solo de las fuentes propias, sino también el aprovechamiento de materiales provenientes de sitios nacionales que aborden cuestiones del territorio.

Sin embargo, en los mensajes no se aprecia un enfoque hacia un público específico, lo que pone en duda la definición del público-meta del sitio, cuestión que se corresponde con los resultados de la encuesta a los periodistas, quienes en su totalidad reconocieron que desconocen a quien va dirigida la producción informativa de la web, un criterio que también emanó durante las entrevistas realizadas a uno de los editores y a una de las reporteras que tributa directamente al sitio. Ello sin dudas afecta la dimensión participativa de la web 2.0 pues se está desconociendo al otro actor importante del proceso comunicativo para estos entornos. Todo lo cual guarda relación con lo anteriormente analizado sobre las constricciones que sobre la producción comunicativa resultante hace la mediación institucional, particularmente lo referido a la normatividad, en tanto toda

Mediaciones Sociales, № 13, 2014, pp. 3-36. ISSN electrónico: 19890494. 
«Mediación de las lógicas de producción hipermedia en el uso de la web 2.0 en Radio Sancti Spíritus. Un estudio de caso cubano»

acción de esta índole sobre la actividad de comunicación pública necesariamente tiene que pasar por los públicos, accesibilidad de estos, sus necesidades e intereses, y no solo por los motivos y aspiraciones de los productores (emisores), sino por el propio derecho ciudadano que estas prácticas están acentuando cada vez más. Ello además habla de un total desconocimiento institucional e individual de los presupuestos esenciales del proceso comunicativo que tiene que ver, igualmente con lo estructural organizativo y cognitivo. Mediaciones, tanto institucional como individual.

No obstante, se observa el intento por asimilar en mayor medida las destrezas que favorezcan tales contactos, cuestión que se manifiesta en el sitio estudiado con la creación de opciones, que si bien no resultan representativas del potencial existente, sí dejan ver claras intenciones de favorecer tal dinámica.

De una parte, el usuario tiene la oportunidad de interactuar con el contenido mediante la posibilidad de ofrecer sus consideraciones acerca del tema publicado, solicitar el servicio de notificación de un nuevo post o de un nuevo comentario publicado luego del publicado o divulgado por él. Se le brinda, además, acceso tanto a un sistema de búsqueda disponible en el propio sitio como a los recursos multimedias (fundamentalmente podcasting y fotorreportajes) y los archivos almacenados en él.

Aunque no están definidas en el sitio, existen regulaciones para la publicación de determinados contenidos. Es lo que Martín Serrano (1993) llama "mediación funcional" de los medios de comunicación, o sea aquella que se encarga de ofrecer un espacio informativo para dar cuenta del devenir socioeconómico, político y cultural.

La web denota, por el contrario, debilidades en esta dirección que, de resolverse, pudieran enriquecer las propuestas participativas de los internautas mediante la incorporación de otros recursos válidos, como gráficos, encuestas relacionadas con la temática que se aborda, o la jerarquización informativa a partir de criterios de usuario mediante opciones de votación. Aquí se confirma como la mediación cognitiva se torna constriñente.

Con respecto al emisor, la observación practicada a las rutinas del sitio evidenció que el usuario se ve más limitado porque solo tiene acceso a través de la sección «Contacto», que ofrece la posibilidad de remitir sus

Mediaciones Sociales, № 13, 2014, pp. 3-36. ISSN electrónico: 19890494.

DOI: http://dx.doi.org/10.5209/rev_MESO.2014.n13.49431 
«Mediación de las lógicas de producción hipermedia en el uso de la web 2.0 en Radio Sancti Spíritus. Un estudio de caso cubano»

criterios a la dirección postal, por vía telefónica o mediante un "mensaje al equipo de Radio Sancti Spíritus", que, como el correo electrónico disponible al final de cada página, resulta un tanto despersonalizado, lo que no estimula su uso. Ello reafirma lo constriñente que resulta la mediación estructural.

Una de las vías que pudiera contribuir a resolver cuestiones que se presentan en el sitio, de acuerdo con la información recopilada a través de las encuestas, la observación y las entrevistas, pudiera ser la socialización de saberes, un recurso de valía para el intercambio de conocimientos, tanto entre el personal directamente vinculado al sitio como el de la redacción tradicional o el de otros sitios de la provincia. Sin embargo, ese proceder no evidencia la sistematicidad requerida.

A pesar de que los directivos entrevistados señalan que se realizan las valoraciones pertinentes para proceder a aplicar la estimulación salarial mensual al personal vinculado al sitio, estos no siempre conocen qué aspectos se le reconocen, lo que ratifica la necesidad de revertir la estrategia seguida hasta el momento, y con ello hacer más efectiva la organización, control y transparencia de la gestión. Funciones que corren a cuenta de la acción institucional.

\subsubsection{Tecnicidad}

Después de haber utilizado los servicios de JOOMLA, Radio Sancti Spíritus emigró hacia el sistema de gestión de contenidos (CMS) WordPress, un software libre con prestaciones que responden a los requerimientos de la web espirituana por sus características, que combinan agilidad y facilidades para la organización y actualización de la web, de acuerdo con lo manifestado tanto por el webmaster como por directivos y editores del medio, entrevistados.

La redacción digital dispone de los recursos esenciales para asumir sus funciones. La conectividad se realiza a través de una línea ADSL, que se ha mantenido, por lo general, estable todo el año. El sitio se hospeda en servidores cuyas prestaciones hacen que el proceso de actualización sea casi siempre lento, elemento corroborado durante el proceso de observación.

Mediaciones Sociales, № 13, 2014, pp. 3-36. ISSN electrónico: 19890494. 
Humberto Concepción Toledo et al.

«Mediación de las lógicas de producción hipermedia en el uso de la web 2.0 en Radio Sancti Spíritus. Un estudio de caso cubano»

En la redacción tradicional, se dispone del mínimo elemental que les posibilita tributar al sitio o a las redes sociales, algo para lo que han mostrado disposición, de acuerdo con el criterio de la dirección de la emisora. Sin embargo el medio no posee dispositivos tecnológicos capaces de favorecer el proceso productivo para el sitio. Y como es lógico se evidencia una carencia en la apropiación de la visión de la cultura tecnológica, esa otra arista que complementa la tecnicidad como cuestión de aparatos, y que pasa más por la concepción que se tenga de estos, de su uso, aplicaciones, beneficios y perjuicios en función de la creatividad para asumir la producción comunicativa. Entonces se puede afirmar que esta mediación es tanto constriñente como habilitante de la aplicaciones de la web 2.0 en la emisora provincial. Constriñente porque tanto técnica como tecnológicamente no se logra la trascendencia necesaria para el empleo óptimo de la web 2.0 y todas sus bondades, bien por la carencia de ciertas posibilidades técnicas para el hacer, bien por pobre creatividad a la hora de la construcción discursiva como un todo con lo que se dispone y de establecer los necesarios vínculos con sus públicos. Habilitante porque ha permitido una producción, que más allá de limitaciones, ha ido incorporando técnicas y con ellas modos de hacer de manera paulatina y por tanto productos con capacidad de satisfacer necesidades de emisión, si bien no del todo en la recepción.

\subsubsection{Cognitivas}

El análisis de contenido deja ver resultados de los que se desprenden distintas aristas de razonamiento. Por una parte, se muestra en conjunto un determinado equilibrio entre los materiales de producción propia (53 $\%)$ y los de agencias externas (prevalece Prensa Latina por encima de la Agencia de Información Nacional) y otros medios (fundamentalmente Cubasí). Estos últimos aportan mayormente los materiales de corte nacional e internacional, aunque algunas de estas temáticas son abordadas por colaboradores del sitio. Los materiales de producción propia, denotan un elevado aporte de los colaboradores. De ello se desprende que la producción propia para el sitio recae fundamentalmente en los 8 colaboradores y las dos reporteras vinculadas específicamente a la Web (59\%), mientras que la contribución del resto de los periodistas de la redacción tradicional fue prácticamente nula.

Ese saldo se corresponde con la apreciación derivada de la encuesta realizada a los reporteros, quienes reconocieron que los trabajos de su

Mediaciones Sociales, Nº 13, 2014, pp. 3-36. ISSN electrónico: 19890494.

DOI: http://dx.doi.org/10.5209/rev_MESO.2014.n13.49431 
«Mediación de las lógicas de producción hipermedia en el uso de la web 2.0 en Radio Sancti Spíritus. Un estudio de caso cubano»

autoría que mayormente se publican en el sitio resultan los mismos que se difunden en los informativos del medio tradicional y son tomados por los propios editores, sin que intervenga la propuesta de ellos ni de sus jefes inmediatos. De ahí que una tercera parte de los encuestados refiriera que nunca reciben el encargo de producir contenidos específicos para la web, una cuantía similar considera que esas demandas solo se hacen a los colaboradores y el resto respondió que solo a veces o casi nunca.

Con respecto al acontecer, en los materiales prima la actualidad por encima de la novedad, porque el sitio hereda las dificultades que al respecto se manifiestan en el medio tradicional en cuanto a los valores-noticia. Una de las reporteras de la web entrevistada para esta investigación reconoce "pudiera pensarse, al interior de la redacción, en maneras de producir contenidos donde se apele más al valor noticia interés humano toda vez que se está traspolando a Internet el lenguaje oficialista, donde las cifras y los datos apartan a las personas de las noticias, la deshumanizan”. El sitio evidencia, además, una dependencia muy estrecha de la agenda del medio tradicional.

Estos resultados evidencian que la mediación cognitiva es más constriñente que habilitante en la producción comunicativa resultante, sobre todo por el desconocimiento que se tiene de los rasgos, posibilidades y exigencias que establece el nuevo soporte y la técnica que lo sustenta, la cual no puede bajo ningún concepto aceptar discursos con viejos formatos y habitus tradicionales.

\subsubsection{Estructurales}

En tiempos en que las mediaciones tecnológicas constituyen un obstáculo a salvar para el mejor funcionamiento de los sitios digitales en $\mathrm{Cu}-$ ba, la preparación del personal vinculado a esa labor adquiere mayor significación para conseguir un producto más completo, dotado de todas las posibilidades comunicativas que ofrece Internet.

De forma general las redacciones muestran carencias en cuanto a la profesionalización de los recursos humanos disponibles. Si bien la totalidad de los encuestados coincide en reconocer la existencia de diferencias al escribir para Internet con respecto al medio tradicional, el 44 por ciento admite no haber recibido ninguna preparación para trabajar para la web,

Mediaciones Sociales, N 13, 2014, pp. 3-36. ISSN electrónico: 19890494.

DOI: http://dx.doi.org/10.5209/rev_MESO.2014.n13.49431 
«Mediación de las lógicas de producción hipermedia en el uso de la web 2.0 en Radio Sancti Spíritus. Un estudio de caso cubano»

mientras el 67 por ciento, señala no haber recibido adiestramiento alguno para insertarse en las redes sociales. Tampoco lo han buscado, ni por vías tradicionales, ni por las más modernas, léase cursos a distancia en la propia web o simplemente mediante una práctica activa en tiempo real que resulta también una forma de aprendizaje.

Ello se corresponde con el escaso uso que se hace en la web de la emisora estudiada de los recursos hipermediales y en el bajo perfil de las propuestas que ofreció la mayoría de los encuestados para mejorar la interactividad del sitio y su funcionamiento integral, lo que denota la necesidad de hacer de la superación una de las primeras divisas para fortalecer el desempeño en este campo, a pesar de que con anterioridad se han realizado acciones. A ello se debe sumar la motivación y exigencia por una labor individual más proactiva.

El análisis de contenido revela más allá de la arquitectura del sitio que la web exhibe un predominio casi absoluto de los géneros tradicionales en las propuestas que pone al alcance en los internautas, quienes mayormente encontrarán informaciones en detrimento de otros géneros tradicionales, como la entrevista, el comentario, la reseña y el reportaje, de los que también se encontraron evidencias, aunque escasas.

Los géneros emergentes, sin embargo, denotan una baja presencia, limitada en el período evaluado a tres fotorreportajes, dos en la primera semana y uno en la segunda. Tal resultado se corresponde con la apreciación de la jefa de la redacción digital: "El género que predomina es la información en texto y el podcasting".

Los elementos referidos reafirman la necesidad de fortalecer la capacitación del personal encargado de la producción específica para el medio como una de las vías que pudiera contribuir a conseguir la transformación necesaria en aras de dotar al sitio de un lenguaje propio, en correspondencia con las variantes que hoy se conciben para las webs periodísticas.

Ello debe incidir de forma positiva en la morfología de los productos comunicativos en cuanto a la hipertextualidad, la interactividad y la multimedialidad, recursos expresivos que, de acuerdo con el análisis de contenido realizado, hoy manifiestan un pobre uso y hacen que la web evidencie un comportamiento más cercano al de la fase de volcado del medio tradi-

Mediaciones Sociales, N 13, 2014, pp. 3-36. ISSN electrónico: 19890494.

DOI: http://dx.doi.org/10.5209/rev_MESO.2014.n13.49431 
Humberto Concepción Toledo et al.

«Mediación de las lógicas de producción hipermedia en el uso de la web 2.0 en Radio Sancti Spíritus. Un estudio de caso cubano»

cional que al que debe caracterizar al sitio digital con sus atributos pertinentes.

De forma general, en el sitio resultan exiguas las manifestaciones de hipertextualidad, las cuales se limitan a muy escasos enlaces documentales, ubicados mayormente fuera del texto que remiten a fotorreportajes o determinados videos, estos últimos publicados por lo general en otros sitios.

Ello se opone a lo planteado en la Carta de Estilo, la que recomienda explícitamente "utilizar las ventajas del hipertex to", y el principio de selectividad del internauta, quien debe contar con la opción de acceder o no al enlace que se propone, que debe contribuir a multiplicar las posibilidades de escritura y lectura, crear nuevas formas narrativas y conectar con diversas fuentes. Lo fundamental sería garantizar la navegabilidad adecuada para evitar que el usuario se pierda en las propuestas que se le facilitan y no disponga con claridad de las herramientas que le permitan regresar al punto de origen, como recomiendan los estudiosos del tema.

Por la vía del análisis de contenido se puso de manifiesto, además, que el sitio consigue algunas evidencias de multimedialidad, con su manifestación más reiterada en la inclusión de imágenes fijas carentes de identificación, que se utilizan como complemento del texto. El mayor avance en este campo se localiza en el empleo del audio en materiales bajo demanda, un recurso del medio que se aprovecha por debajo del potencial existente pero que denota progresos que pudieran tener un empleo más allá de lo meramente informativo, para hacerse sentir como complemento de otros materiales.

En el terreno de la interactividad la web estudiada evidencia posibilidades que no siempre se explotan, según se desprende de la observación practicada. Desde el punto de vista tecnológico, el sitio da la posibilidad al internauta de contactar con los editores, realizar sus comentarios a cada uno de los materiales que se publican, compartirlos en las redes sociales y suscribirse por correo electrónico y a través del canal RSS.

De acuerdo con los resultados de la encuesta a los periodistas y a los editores del sitio, se manifiestan fallas en el reconocimiento de estas opciones, pues por lo general solo hacen referencia a los comentarios y al correo

Mediaciones Sociales, № 13, 2014, pp. 3-36. ISSN electrónico: 19890494.

DOI: http://dx.doi.org/10.5209/rev_MESO.2014.n13.49431 
Humberto Concepción Toledo et al.

«Mediación de las lógicas de producción hipermedia en el uso de la web 2.0 en Radio Sancti Spíritus. Un estudio de caso cubano»

electrónico como las vías por donde se puede concretar ese importante recurso, distintivo del medio digital y que cada día gana en solidez universalmente, toda vez que la razón de ser de este soporte comunicativo son sus audiencias, algo en lo que poco piensan quienes laboran para la web analizada.

El análisis de contenido permitió corroborar que muchas de estas opciones son poco explotadas por los internautas, resulta muy escaso el número de comentarios publicados y las remisiones a las redes sociales, por lo que se hace necesario trabajar con mayor intencionalidad para fortalecer los nexos con quienes acuden al sitio.

Al respecto, los periodistas de la redacción tradicional encuestados concentraron sus sugerencias para ganar en este terreno en: responder a los comentarios de los lectores, tratar de hacer coincidir las propuestas informativas con los intereses de los cibernautas, enriquecer los contenidos, ajustarse más a los lineamientos del medio digital y contar con superiores niveles de actualización de la página.

Mediante la observación de las rutinas del medio se pudo conocer que en el caso de los comentarios, se recibe un número considerable de mensajes Spam cada día, que son eliminados casi masivamente, lo que resta tiempo para atender los que pudieran resultar útiles al sitio.

Con respecto a la posibilidad de lograr una mayor correspondencia entre los intereses de los internautas y las propuestas informativas de la web, la directora del medio estimó que realmente no se intenciona el seguimiento de este aspecto, aunque reconoce las ventajas de tenerlo en consideración para promover el tratamiento de aquellos temas que más visitas al sitio provocan.

Sin duda alguna lo estructural es una mediación tanto habilitante como constriñente sobre la producción comunicativa, y más que eso, los resultados que se obtienen en la relación con los públicos, una de las exigencias que tiene hoy este soporte para materializar nuevos procesos de comunicación de obligatoria interactividad.

\subsection{Mediaciones externas:}

Mediaciones Sociales, № 13, 2014, pp. 3-36. ISSN electrónico: 19890494. 
Humberto Concepción Toledo et al.

«Mediación de las lógicas de producción hipermedia en el uso de la web 2.0 en Radio Sancti Spíritus. Un estudio de caso cubano»

\subsubsection{Económicas}

Si bien la existencia de medios digitales en Cuba resultaba un hecho consumado cuando en 2005 se aprobó la Resolución $\mathrm{N}^{\circ} 89$ del Ministerio de Trabajo y Seguridad Social, ese documento no recoge precisiones que particularicen en toda su magnitud esta arista del desempeño periodístico.

A su favor puede señalarse el hecho de que avanza con respecto a sus precedentes en el sentido de que, en su artículo 2, inciso e), reconoce como "prensa digital" a lo que con anterioridad se daban en llamar "publicaciones electrónicas", cuestión que denota, por un lado una mayor correspondencia con la realidad que distingue a la prensa cubana luego de transcurridos los primeros años del siglo XXI, y por otro un acercamiento al discurso académico y profesional que expresa mayor conocimiento sobre el particular.

El documento, sin embargo, no avanza en el resto de su cuerpo de la misma manera, por cuanto insiste en muchas de sus partes en las regularidades de sus antecesores, al tomar en cuenta un grupo de elementos que los reconoce como aptos para ser considerados como "pagos adicionales" dentro de la conformación del sueldo mensual del periodista (por dirigir un equipo de trabajo en exteriores, la radio o la televisión; por dirigir o conducir programas informativos en la radio y la televisión; por el uso sistemático de un idioma extranjero en función del trabajo), pero evidencia limitaciones con respecto al periodismo hipermedia y el personal encargado de asumirlo desde distintas funciones.

Esta es una mediación que resulta más constriñente que habilitante y agregaríamos que muy compleja por su grado de determinación en los procesos productivos de comunicación, los cuales no pueden perder de vista su carácter empresarial y no confundir su carácter industrial con la rentabilidad de la producción que a ello ha impuesto el capitalismo. La producción comunicativa necesita de adecuados resortes económicos para su re-producción material y como es lógico simbólica.

\subsubsection{Políticas}

\subsubsection{Contexto político}

Mediaciones Sociales, № 13, 2014, pp. 3-36. ISSN electrónico: 19890494. 
Humberto Concepción Toledo et al.

«Mediación de las lógicas de producción hipermedia en el uso de la web 2.0 en Radio Sancti Spíritus. Un estudio de caso cubano»

Para el ejercicio del periodismo en Cuba no se puede obviar la fuerte mediación que ha ejercido y ejerce el diferendo Cuba-Estados Unidos que data de poco más de 140 años y que sitúa a la prensa cubana en un terreno en el que persisten la injerencia política, las permanentes campañas mediáticas, el constante ocultamiento de la verdad y el afianzamiento de la mentira en torno a la realidad de la isla, un propósito que tienen entre sus principales plataformas de concreción la guerra radial y televisiva que con fondos millonarios se sostiene desde Estados Unidos y que se apoya en quienes desde el interior del país actúan la mayor parte de las veces pagados para tales fines por el gobierno norteamericano.

De igual forma, el presidente del Consejo de Estado y de Ministros de la República, Raúl Castro (2012) ha señalado que "Si hemos escogido soberanamente, con la participación y respaldo del pueblo, la opción martiana del partido único, lo que nos corresponde es promover la mayor democracia en nuestra sociedad (...), lo que presupone fomentar un clima de máxima confianza y la creación de las condiciones requeridas en todos los niveles para el más amplio y sincero intercambio de opiniones (...), favoreciendo que las discrepancias sean asumidas con naturalidad y respeto, incluyendo a los medios de comunicación masiva (...), los que deberán involucrarse con responsabilidad y la más estricta veracidad en este empeño, no al estilo burgués, lleno de sensacionalismo y mentiras, sino con comprobada objetividad y sin el secretismo inútil”.

Este escenario político, mediación importante de los procesos de producción comunicativa pública soportado en medios, no puede ser más complejo. Como afirma el profesor e investigador Martín Barbero: "Si hablar de cultura política significa tener en cuenta las formas de intervención de los lenguajes y las culturas en la constitución de los actores y del sistema político, pensar la política desde la comunicación significa poner en primer plano los ingredientes simbólicos e imaginarios presentes en los procesos de formación y consolidación del poder. Lo que deriva la democratización de la sociedad hacia un trabajo en la propia trama cultural y comunicativa de la política. Pues ni la productividad social de la política es separable de las batallas que se libran en el terreno simbólico, ni el carácter participativo de la democracia es hoy real por fuera de la escena pública que construye la comunicación masiva (mediática)" (2002-b:16).

\subsubsection{Política informativa}

Mediaciones Sociales, № 13, 2014, pp. 3-36. ISSN electrónico: 19890494. 
«Mediación de las lógicas de producción hipermedia en el uso de la web 2.0 en Radio Sancti Spíritus. Un estudio de caso cubano»

La realización del IX Congreso de la Unión de Periodistas de Cuba en julio de 2013 trajo una vez más a primer plano las aristas que inciden en la implementación de la política informativa en el país: si bien hay consenso en torno a la incidencia que en ella tiene el diferendo Cuba - Estados Unidos, también resultan evidentes constantes limitaciones en el acceso a las fuentes de información, motivadas en ocasiones por el interés de no aportar elementos que puedan servir al enemigo y en otros por reconocidas debilidades en la cultura comunicacional dentro de nuestras fronteras.

El asunto ha mantenido un constante tratamiento durante las más trascendentes acciones del sistema político en los últimos años. A pesar de ello, persisten incongruencias en este sentido con incidencia directa en la política informativa, la cual debe ofrecer una respuesta en correspondencia con los desafíos que se presentan en el país dentro del actual proceso de transformaciones del modelo económico. Al respecto se ha señalado: "O la prensa cubana se convierte en una plaza pública por excelencia para visibilizar, dar forma y alentar el consenso en torno al cambio de mentalidad, o asumiremos el costo de que parte de esos consensos se articulen progresivamente al margen de nuestros medios". (Garcés, R., 2013: 11).

De ahí que esta mediación sea tan importante y estratégica, y sin embargo continúa siendo constriñente al desarrollo de una labor periodística en general, y particularmente en el periodismo hipermedia, más aún con el uso de la web 2.0 con el costo que ello implica, pues esta forma de hacer ofrece las bondades para eso que tanto políticos como académicos de nuestro país reconocen como necesario para la sociedad cubana actual: la participación ciudadana responsable y transformadora.

\subsubsection{Tecnológicas}

Cuba entró a partir de 1996 en un proceso en el que se dan los primeros pasos para el ordenamiento de un trabajo continuo en aras de impulsar el uso y desarrollo de las Tecnologías de la Información y las Comunicaciones, que encuentra un avance concreto con la aprobación un año después de los Lineamientos Generales para la Informatización de la Sociedad.

Mediaciones Sociales, № 13, 2014, pp. 3-36. ISSN electrónico: 19890494. 
«Mediación de las lógicas de producción hipermedia en el uso de la web 2.0 en Radio Sancti Spíritus. Un estudio de caso cubano»

De acuerdo con datos de la Unión Internacional de Telecomunicaciones (2010), Cuba presenta un nivel de uso individual de Internet de 111 por cada mil habitantes, cifra muy inferior a la realidad cuando se considera el uso social derivado de la conexión desde centros científicos, de la salud, la educación, medios de prensa y el sector artístico, por citar los más representativos.

Restricciones de orden tecnológico y financiero limitan la conectividad a un proveedor internacional que reduce a un Gigabyte el acceso del país a Internet, capacidad alcanzada con la entrada en funcionamiento del cable de fibra óptica procedente de Venezuela a través del mar Caribe.

En menos de una década se ha logrado abarcar, con limitaciones tecnológicas, a más de 600 mil receptores de una señal a la que el país llegó tarde, fundamentalmente por el bloqueo económico, comercial, financiero y tecnológico impuesto por más de medio siglo contra Cuba por el gobierno de Estados Unidos.

A diferencia de la gran mayoría de los países del mundo, donde los suministradores de Internet basan el incremento de sus cuentas en la venta del servicio, en Cuba se priorizan los servicios económicos y sociales, con énfasis en educación, salud e investigaciones, lo que no excluye que las nuevas inversiones busquen satisfacer la creciente demanda de conexión.

Según datos de la Empresa de Telecomunicaciones de Cuba (2013), entre 2008 y 2013 se invirtieron en el país 44 millones de dólares para la optimización de un servicio que cuenta con una demanda potencial de más de medio millón de computadoras y que tiene entre sus prioridades el logro de una mayor integración de las redes nacionales con el objetivo de aumentar los niveles de tráfico, una proyección que enfrenta dificultades materiales y restricciones propias de una demanda superior a la oferta.

En esta dirección, en la actualidad el país dispone de 121 salas de navegación, desde las que se puede acceder a redes sociales, como Facebook y Twitter, como parte de una estrategia encaminada al incremento de los servicios de Internet a la población, que se suma a los servicios sociales desarrollados hasta ahora.

Mediaciones Sociales, Nº 13, 2014, pp. 3-36. ISSN electrónico: 19890494. 
Humberto Concepción Toledo et al.

«Mediación de las lógicas de producción hipermedia en el uso de la web 2.0 en Radio Sancti Spíritus. Un estudio de caso cubano»

Entre esas alternativas sobresale Infomed, Red Telemática de la Salud en Cuba, que incluye entre sus principales prestaciones el acceso a una biblioteca virtual, la disponibilidad de importantes bases de datos especializadas de diversa procedencia, así como libros, revistas médicas cubanas, boletines y manuales de procedimiento de diferentes disciplinas.

A la vez, la creación de la red universitaria nacional (REDUNIV), posibilitó interconectar 130 facultades del país y 460 departamentos docentes, además de satisfacer las necesidades esenciales del Ministerio de Educación Superior, entre ellas garantizar la comunicación entre las instituciones nacionales e internacionales, fundamentalmente por correo y chat, así como respaldar procesos sustantivos de la educación superior, como la extensión universitaria.

De igual forma, el Centro Nacional de Informática en la Cultura (CUBARTE) dispone de un portal que brinda servicio básico de correo electrónico y navegación nacional, del que se benefician cientos de instituciones en todos los municipios de la isla, así como un amplio número de intelectuales y artistas, quienes cuenta con una vía de difusión e intercambio de información temática y especializada.

A pesar de las limitaciones, en el sector de la prensa se registran avances significativos en cuanto a la presencia en Internet. Para 2013, 133 medios se encuentran en Internet, como parte de una estrategia encaminada más a consolidar esas propuestas que a incrementar exponencialmente su número, de acuerdo con datos publicados por la Unión de Periodistas de Cuba (2013: 10).

La propia fuente reconoce que en esa dirección también repercute el ascenso del número de periodistas conectados desde sus casas, que al cierre de marzo de 2013 beneficiaba a 1899 colegas, 251 de ellos mediante líneas ADSL, de mayores posibilidades de enlace a la red.

Propiamente en el terreno de los medios, la disponibilidad de Sistemas de Gestión de Contenidos descansa fundamentalmente en la asimilación del software libre disponibles en la red sobre la base de la experimentación, como ha sucedido, por ejemplo, con el tránsito por Plone, Joomla y ahora por Wordpress, mientras sigue ausente la opción de disponer de uno que se ajuste a las necesidades de los medios de la isla.

Mediaciones Sociales, N 13, 2014, pp. 3-36. ISSN electrónico: 19890494.

DOI: http://dx.doi.org/10.5209/rev_MESO.2014.n13.49431 
«Mediación de las lógicas de producción hipermedia en el uso de la web 2.0 en Radio Sancti Spíritus. Un estudio de caso cubano»

Si bien es cierto que ha faltado en algunos casos visión estratégica con el uso de los CMS, a partir de que las soluciones no siempre se han ajustado al nivel de preparación del personal ni a las opciones de conectividad de los medios, las variantes puestas en práctica han demostrado sus potencialidades en cuanto a la agilidad del proceso de emisión noticiosa, mejoras en el posicionamiento y el uso más eficiente de los recursos.

Según expertos en el tema la cuestión de la prensa cubana en Internet, es más falta de iniciativa y de decisiones que de tecnología. Hay muchas cosas que se pueden hacer solo con colocar un enlace con otro sitio cubano y ponerle un ambiente que se parezca a mi página, y para un usuario común y corriente en Internet, es un video de ese medio y no de otro, lo que le interesa es ver ese video. En resumen, si hay más recursos, mucho mejor, pero creo que todavía falta preparación para incluso aprovechar más recursos si los hubiera.

Todo ello ratifica análisis anteriormente realizados donde se reconoce lo habilitante de la tecnicidad a pesar de limitaciones en lo interno, que ahora se hace patente también en lo externo. Pero lo constriñente que resulta la visión tecnológica, o sea aquella que opera con la capacidad creativa de hacer nuevas cosas, factibles por demás, que tienen que ver más con los contenidos, discursos, y lenguajes propios de esta técnica que exigen más que todo una disposición favorable al cambio, al autoaprendizaje, a la experimentación.

\section{CONCLUSIONES}

1.- Las lógicas de producción hipermedia se diferencian de las tradicionales precisamente por las modificaciones que las tecnologías de la información y la comunicación introducen en la producción, circulación y apropiación de la información, al tener lugar procesos que se distinguen en cuanto al lenguaje hipertextual, multidireccional, interactivo y multimedial.

2.- En esta dirección, la web 2.0 ha redimensionado las posibilidades expresivas del ciberespacio, a partir de la evolución tecnológica de las aplicaciones tradicionales a herramientas participativas. Su carácter social y colaborativo está modificando las relaciones de los ciudadanos con las

Mediaciones Sociales, № 13, 2014, pp. 3-36. ISSN electrónico: 19890494.

DOI: http://dx.doi.org/10.5209/rev_MESO.2014.n13.49431 
Humberto Concepción Toledo et al.

«Mediación de las lógicas de producción hipermedia en el uso de la web 2.0 en Radio Sancti Spíritus. Un estudio de caso cubano»

Tecnologías de la Información y la Comunicación, los modos comunicativos e incluso los modelos de negocio, en un proceso en el que los medios y sus públicos no están exentos de la transformación del espacio navegacional que se inició en el 2004.

3.- Como organización mediática, Radio Sancti Spíritus resulta una emisora de carácter provincial, líder de un sistema territorial conformado por otras seis plantas municipales y que desde inicios del siglo XXI dispone de un sitio digital que ha demandado la incorporación de nuevas prácticas de producción comunicativa.

4.- Luego de más de una década de inserción en el terreno digital, en la web de Radio Sancti Spíritus:

\section{1.- En el plano Interno:}

4.1.a.- Se manifiesta una incipiente cultura del periodismo hipermedia, como un elemento emergente que tiene que enfrentar la resistencia al cambio de la cultura profesional dominante y de las culturas organizacionales establecidas en el medio, abocadas a una reconfiguración ante el emplazamiento de las tecnologías y prácticas que necesitan ritos y aprendizajes nuevos.

4.1.b.- En el orden institucional, las lógicas de producción median a la cultura profesional a través del predominio de la redacción tradicional sobre la digital, impidiendo la necesaria convergencia y que implica limitaciones en la producción propia para la web, indefinición en la agenda informativa, la estrategia editorial y el público-meta, falta de sistematicidad en la socialización de saberes y experiencias, y restricciones en la política de estimulación salarial.

4.1.c.- Desde el punto de vista tecnológico, si bien Radio Sancti Spíritus no dispone de un Sistema de Gestión de Contenidos (CMS) propio de la prensa cubana, la utilización del Wordpress (software libre) aporta prestaciones que, junto a la disponibilidad de un aceptable equipamiento informático y otros aseguramientos importantes, como grabadoras y una cámara fotográfica, contribuye a habilitar conocimientos y hábitos respecto al uso de las tecnologías y crea bases para consumar una producción con mayores características hipermediales. Ello, sin embargo, se ve limitado en

Mediaciones Sociales, № 13, 2014, pp. 3-36. ISSN electrónico: 19890494.

DOI: http://dx.doi.org/10.5209/rev_MESO.2014.n13.49431 
Humberto Concepción Toledo et al.

«Mediación de las lógicas de producción hipermedia en el uso de la web 2.0 en Radio Sancti Spíritus. Un estudio de caso cubano»

el campo estructural como consecuencia de las insuficientes competencias para manejar adecuadamente los recursos expresivos y las herramientas de Internet; las carencias en el uso de la interactividad, la multimedialidad y la hipertextualidad; y el escaso uso de los géneros hipermediales, que descansa básicamente en el podcast y el fotorreportaje.

4.1.d.- En el campo cognitivo encuentra evidencias en las restricciones derivadas de una actualización discontinua y en una limitada producción propia para la web, que se nutre mayormente del "volcado" desde una redacción tradicional mediada institucionalmente por limitaciones en cuanto a las exigencias en torno a las lógicas de producción hipermediales, destacándose el poco margen hacia la necesaria autoregulación que de manera dialéctica interactúe con los marcos regulatorios externos e institucionales en pos de un mejor desempeño profesional.

\section{2.- En el plano externo:}

4.2.a.- Sobre la web de Radio Sancti Spíritus se manifiestan mediaciones externas vinculadas a una política salarial desactualizada, los límites que impone la política informativa o su inadecuada aplicación, el insuficiente nivel de acceso a Internet y el reducido ancho de banda disponible.

5.- De manera general se puede concluir que tanto las mediaciones internas como externas han estado articulando de manera dialéctica, o sea con movimientos progresivos y/o regresivos, por tanto contradictorios, la evolución de las webs tradicionales hacia nuevas concepciones centradas en el usuario como eje del proceso comunicativo en Radio Sancti Spíritus. La habilitación se evidencia en discretos avances en la filosofía 2.0, que hasta ahora implican un mayor progreso en la disponibilidad de las aplicaciones requeridas para una mayor participación de los internautas que en las concepciones propias para lograr ese objetivo. A la vez las constricciones que también han provocado, han marcado a los productos comunicativos de manera que no expresan en toda su dimensión las transformaciones e innovaciones que prometen y permiten las tecnologías en el periodismo para y con Internet.

6.- Sin dudas la proposición para estudiar lógicas de producción periodísticas en la web y sus mediaciones internas y externas formuladas con antelación por las autoras cubanas Diz y Saladrigas (2011) resulta una

Mediaciones Sociales, № 13, 2014, pp. 3-36. ISSN electrónico: 19890494.

DOI: http://dx.doi.org/10.5209/rev_MESO.2014.n13.49431 
Humberto Concepción Toledo et al.

«Mediación de las lógicas de producción hipermedia en el uso de la web 2.0 en Radio Sancti Spíritus. Un estudio de caso cubano»

herramienta valiosa para su abordaje que para la presente investigación mostró su pertinencia y capacidad metodológica.

\section{Bibliografía}

Bello, L. (2014). Directora. Emisora Provincial Radio Sancti Spíritus. Entrevista personal. Inédita. Realizada: 10 de enero. Sancti Spíritus.

Castro, R. (2012). Discurso clausura de la I Conferencia Nacional del PCC, 29 de enero de 2012, [Internet]. Disponible en:

http://www.cuba.cu/gobierno/rauldiscursos/2012/esp/r290112e.html [Consultado el 8 de octubre de 2013].

CEBRIÁn, M. (2008-a). «La Web 2.0 como red social de comunicación e información», en Revistas Científicas Complutenses Vol. 14 [Internet] Disponible en:

http://revistas.ucm.es/index.php/ESMP/article/view/ESMP080811034 5A/11928. [Consultado el 5 de septiembre de 2012] pp. 2-14.

DíAZ, D. y L. GARCía CHICO (2009). Web 2.0 y periodismo: del yo-rey al nosotros-red. Trabajo de Diploma para la Licenciatura en Periodismo. La Habana. Facultad de Comunicación, Universidad de La Habana.

DIZ, E. (2011). Reubicar el futuro. Las mediaciones entre la cultura profesional y las lógicas de producción periodísticas para la web. Estudio de casos: Granma y Trabajadores. Tesis en opción al grado de Doctor en Ciencias de la Comunicación. La Habana. Facultad de Comunicación, Universidad de La Habana.

Diz, E. y SAladrigas, H. (2011): «La categoría mediaciones en los análisis de las lógicas de producción periodísticas en la web», Mediaciones Sociales. Revista de Ciencias Sociales y de la Comunicación, $n^{\circ}$ 9, pp. 35-72. DOI: http://dx.doi.org/10.5209/rev_MESO.2011.n9.38010

Gallego PÉRez, J. Ignacio (2010). Podcasting: nuevos modelos de distribución para contenidos sonoros. Barcelona, UOC.

Mediaciones Sociales, № 13, 2014, pp. 3-36. ISSN electrónico: 19890494.

DOI: http://dx.doi.org/10.5209/rev_MESO.2014.n13.49431 
Humberto Concepción Toledo et al.

«Mediación de las lógicas de producción hipermedia en el uso de la web 2.0 en Radio Sancti Spíritus. Un estudio de caso cubano»

GARCÉs, Raúl (2013). «Tesis sobre la prensa cubana». En Enfoque, Edición extraordinaria, agosto de 2013. La Habana, Editorial Pablo de la Torriente, pp. 10-11.

Instituto Cubano de Radio y Televisión (2005). Carta de Estilo. La Habana.

MARTín BARBERO, J. (2002-b). «Medios, mediaciones y tecnología». En Revista Signo y Pensamiento ${ }^{\circ}$ 41. Volumen XXI, julio-diciembre. Cilbpdfwww.fastio.com [Consultado el 8 de febrero de 2014].

Martín SERrano, M. (1993). «La mediación de los medios de comunicación». En De Moragas, M. (Editor) (1993). Sociología de la Comunicación de Masas. 4 Volúmenes, Volumen I. Editorial Gili, México. Pp. 141-162.

Ministerio de Trabajo y Seguridad Social (2005). Resolución No. 89/2005 Reglamento para la organización salarial de los trabajadores de la prensa. La Habana, Imprenta Alejo Carpentier.

ORIHUELA, J. L. (2002). «Los 10 paradigmas de la e-Comunicación. Máster en Creación y Comunicación Digital». [Internet]. Disponible en: http://mccd.udc.es/orihuela/paradigmas/. [Consultado el 5 de marzo de 2012].

ORTA, Yailin (2013). «Internet por dentro en Cuba» [Internet]. Disponible en:

http://mesaredonda.cubadebate.cu/mesa-redonda/2013/08/08/internetpor-dentro-en-cuba/ [Consultado el 12 de octubre de 2013].

Unión de Periodistas de Cuba (2013). «Informe del Comité Nacional (2008-2013)». En Documentos del IX Congreso, abril de 2013. La Habana, Editorial Pablo de la Torriente, pp. 10-11.

UNIÓN INTERNACIONAL DE COMUNICACIONES (ITU). Measuring de Information Society 2010. ITU, marzo de 2010. Disponible en:

www.tic.gov.md/img/news2010/03/MIS_2010.pdf [Consultado el $12 \mathrm{de}$ octubre de 2013].

Mediaciones Sociales, № 13, 2014, pp. 3-36. ISSN electrónico: 19890494.

DOI: http://dx.doi.org/10.5209/rev_MESO.2014.n13.49431 
Humberto Concepción Toledo et al.

«Mediación de las lógicas de producción hipermedia en el uso de la web 2.0 en Radio Sancti Spíritus. Un estudio de caso cubano»

Watzlawick, P.; J. BeAvin y Don D. JAKSON (1991). Teoría de la comunicación humana. En Universidad Nacional de Tres de Febrero. http://www. UNTREF Virtual [Consultado el 12 de enero de 2014].

\section{PARA CITAR ESTE TRABAJO EN BIBLIOGRAFÍAS:}

Concepción Toledo, Humberto; SAladrigas Medina, Hilda; RodRíguez HerNÁNDEZ, Mirelys (2014): "Mediación de las lógicas de producción hipermedia en el uso de la web 2.0 en Radio Sancti Spíritus. Un estudio de caso cubano", Mediaciones Sociales. Revista de Ciencias Sociales y de la Comunicación, $\mathrm{n}^{\mathrm{o}}$ 13, pp. 3-36. DOI: http://dx.doi.org/10.5209/rev_MESO.2014.n13.49431

RECIBIDO: 07 de noviembre de 2014.

ACEPTADO: 17 de febrero de 2015.

Mediaciones Sociales, № 13, 2014, pp. 3-36. ISSN electrónico: 19890494.

DOI: http://dx.doi.org/10.5209/rev_MESO.2014.n13.49431 
«Mediación de las lógicas de producción hipermedia en el uso de la web 2.0 en Radio Sancti Spíritus. Un estudio de caso cubano»

\section{Los autores}

${ }^{(*)}$ Humberto L. Concepción Toledo es Licenciado en Periodismo (1989) por la Universidad de Oriente. Máster en Ciencias de la Comunicación por la Universidad de Sancti Spíritus (2014). Ha desempeñado labores periodísticas en la radio a nivel provincial y nacional durante más de 25 años, así como en la versión digital del Periódico Provincial Escambray. Por su labor profesional ha obtenido premios y reconocimientos. Desde hace 17 años se desempeña como Presidente de la Unión de Periodistas de Cuba (UPEC) en la provincia cubana de Sancti Spíritus. Se mantiene como periodista en ejercicio, fundamentalmente en el área de las nuevas tecnologías.

${ }^{(* *)}$ Hilda Saladrigas Medina es Licenciada en Filosofía Marxista-Leninista (1988) por la Universidad de Oriente. Master (2003) y Doctora en Comunicación por la Facultad de Comunicación de la Universidad de La Habana (2005). Investigadora de medios y opinión pública desde 1988 y profesora desde 1999. Ha desempeñado labores en centros de investigación y la propia Facultad de Comunicación de la Universidad de La Habana. Por su desempeño profesional ha obtenido numerosos premios y reconocimientos, nacionales e internacionales. Actualmente es Jefa del Departamento/Carrera de Comunicación Social y presidenta del Comité Académico de la Maestría en Comunicación en la Facultad de Comunicación de la Universidad de La Habana. Además es la presidenta de la Comisión Nacional de Carrera de Comunicación Social en Cuba.

${ }^{(* \star *}$ Mirelys Rodríguez Hernández es Licenciada en Contabilidad y Finanzas (1988) por la Universidad Central de Las Villas. Máster en Nuevas tecnologías para la educación (2007) por la Universidad de Sancti Spíritus. Durante su carrera profesional se ha desempeñado como especialista en ciencias informáticas. Es profesora auxiliar de la Universidad de Sancti Spíritus en la carrera de Comunicación Social. Está integrada al Movimiento de Periodistas Docentes e integra el grupo de profesores de la Asociación Cubana de Comunicadores Sociales. Colabora con el sitio web del periódico Escambray y de Enlace, perteneciente a la Unión de Periodistas de Cuba en Sancti Spíritus. Ha impartido y recibido diferentes cursos relacionados con las tecnologías de la información y las comunicaciones y actualmente trabaja en conjunto con la Universidad de Sancti Spíritus en un proyecto sobre el impacto social de las nuevas tecnologías.

Mediaciones Sociales, № 13, 2014, pp. 3-36. ISSN electrónico: 19890494. 